\title{
Variation in Runoff, Suspended Sediment Load, and Their Inter-Relationships in Response to Climate Change and Anthropogenic Activities Over the Last 60 Years: A Case Study of the Upper Fenhe River Basin, China
}

\author{
Luan Zhang ${ }^{1,2, *}$, Suqing Li ${ }^{1,2}$, Zhitao Wu ${ }^{1,2}$, Xiaohui Fan ${ }^{1,2}$, Hongjian Li ${ }^{1,2}$, Qi Meng ${ }^{1,2}$ and \\ Jing Wang ${ }^{3}$ \\ 1 Institute of Loess Plateau, Shanxi University, Taiyuan 030006, China; lisuqing@sxu.edu.cn (S.L.); \\ wuzhitao@sxu.edu.cn (Z.W.); fanxiaohui@sxu.edu.cn (X.F.); hongli@sxu.edu.cn (H.L.); \\ mengqi4028@163.com (Q.M.) \\ 2 Shanxi Key Laboratory for Ecological Restoration of Loess Plateau, Taiyuan 030006, China \\ 3 Institute of Geographic Sciences and Natural Resources Research, CAS, Beijing 100101, China; \\ wangjing@igsnrr.ac.cn \\ * Correspondence: zhangluan@sxu.edu.cn
}

Received: 24 May 2020; Accepted: 15 June 2020; Published: 20 June 2020

\begin{abstract}
The variation of river runoff (Q) and suspended sediment load (S), in addition to their influential factors, is an important area of focus in hydrological sciences. Here, Mann-Kendall tests and double mass curve analyses were used with hydrometric data from four hydrological stations in the upper Fenhe River Basin in China to evaluate temporal trends in annual $Q\left(Q_{a}\right)$ and $S$ $\left(S_{a}\right)$ values between 1955 and 2015. Based on the observed inflection points, three distinct periods were identified, namely, 1955-early 1980s (period I), the early 1980s-1996 (period II), and 1996-2015 (period III). The $Q_{a}$ and $S_{a}$ values for the four stations, except for $Q_{a}$ values for the Jingle station, significantly decreased over the study period, with average reduction rates of $0.68-1.07 \mathrm{~mm} \cdot \mathrm{km}^{-2} \cdot \mathrm{a}^{-1}$ and 9.24-54.39 $\mathrm{t} \cdot \mathrm{km}^{-2} \cdot \mathrm{a}^{-1}$, respectively. Decreased rainfall, implementation of soil and water conservation program, and reservoir construction were primarily responsible for decreased $Q_{a}$ and $S_{a}$ values for the three stations during period II, while the first two factors led to variation in $Q_{a}$ and $S_{a}$ for the Jingle station during the same period. During period III, the $Q_{a}, S_{a}$, and $Q_{a}-S_{a}$ relationships for the four stations were intensively affected by increased anthropogenic activities, including water diversion, cross-basin water transfers, soil and water conservation measures, revegetation efforts, and sand excavation. Further, the $Q_{a}, S_{a}$, and $Q_{a}-S_{a}$ relationships at the Lancun station were affected by the construction of the No. 2 Fenhe Reservoir. Effective water use and supply strategies should be implemented in the future for the upper Fenhe River Basin.
\end{abstract}

Keywords: runoff; suspended sediment load; temporal variation; climate condition; reservoir; coal mining

\section{Introduction}

Climate change and increased anthropogenic activities in recent decades have introduced altered dynamics in river systems, including frequent occurrences of discontinuous flow [1], sharp decreases in suspended sediment loads (S) [2], increasingly strained water supplies [3], and deteriorated river ecologies [4]. Understanding these dynamics and their underlying factors have become areas of intense focus in hydrological research. Indeed, investigations of the variations in runoff (Q) and 
S have been conducted for large global rivers within recent decades, including the Mississippi [5], Nile [6], Amazon [7] Colorado [8], Yangtzi [9], and Yellow Rivers [10]. In addition, several studies have explored factors that influence $Q$ and S. For example, Burn and HagElnur [11] evaluated 18 hydrological variables for 248 Canadian catchments and concluded that variation in hydrological variables was related to variation in meteorological variables. Additionally, Walling and Fang [12] demonstrated that reservoir construction was the primary factor underlying annual S reductions in about $50 \%$ of 145 major global rivers, excluding those in Africa and South America. Furthermore, Restrepo and Escobar [13] observed that dramatic increases in S in the Magdalena River and its tributaries during 1980-2010 were primarily attributed to marked increases in forest clearance.

The Yellow River is one of the most heavily sediment-laden rivers in the world and has been intensively affected by climate change and anthropogenic activities in recent decades [14,15]. The Middle Yellow River is the major sediment source for the Yellow River due to storms in summer, loose loess, hilly and gully landforms, poor vegetation, and unreasonable cultivation. Recently, dramatic changes in $Q$ and $S$ values in most of its tributaries have been observed [16]. Several factors have been implicated in the spatiotemporal changes of $Q$ and $S$ of the Middle Yellow River, including the El Nino/Southern Oscillation climate pattern [17], weakened summer monsoons [18], hydraulic engineering [19], soil and water conservation activities [14], water diversion, and sand excavation [20]. These factors may also alter the hydrologic response between $\mathrm{Q}$ and $\mathrm{S}$ (i.e., the Q-S relationship) that can be used to provide information to understand fluvial system behaviors and long-term trends, while also providing context for interpreting short-term events within a basin [21-23]. Scaling effects are some of the most important characteristics underlying fluvial system behaviors [7,24,25], where the dynamics of $Q, S$, and the Q-S interactions may vary across areas and among different periods in response to factors within tributary basins [26]. Consequently, it is necessary to investigate the basin-scale temporal variation in $\mathrm{Q}, \mathrm{S}$, and the Q-S relationships that are critical for predicting future trends in $\mathrm{Q}$ and $\mathrm{S}$, in addition to informing effective management strategies for promoting river health and the sustainable utilization of water resources that is coordinated with economic development.

The Fenhe River is the second-largest tributary of the Yellow River, with a length of $710 \mathrm{~km}$. The Fenhe River historically had appropriate conditions for boating and well-developed transportation activities. Indeed, its lower reaches were still viable for boating transport until 1929. However, discontinuous flow was first detected in the Middle Fenhe River in 1958 and has frequently occurred in various sections of the river in recent decades. By the end of the 1990s, critical water scarcity problems were occurring in the upper Fenhe River Basin [27]. Concomitantly, warming and drying climate trends were detected in this region during this period [28], while large reservoirs and several coal mining bases were established in the Fenhe River Basin. To alleviate serious soil erosion and improve the environment, the national level "Soil and Water Conservation," "Natural Forest Protection," and "Grain for Green" programs were successively implemented within the basin. Furthermore, a large-scale, cross-basin water transfer project was implemented in the early 21st century to meet the increasing water demands. Given these increasingly complex and interactive factors and processes in the basin, two essential questions have remained: How have $Q$ and $S$ values varied within the upper Fenhe River Basin over the past 60 years? Furthermore, how have $\mathrm{Q}$ and $\mathrm{S}$, as well as the $\mathrm{Q}-\mathrm{S}$ relationships, varied in response to climate change and anthropogenic disturbances? The present study addresses these questions using an in-depth analysis of annual $Q\left(Q_{a}\right)$ and $S\left(S_{a}\right)$ datasets from 1955 to 2015 for four major hydrological stations in the upper Fenhe River Basin, which is a unique basin that is a water supply source for the provincial capital city with 4.46 million people and a large coal mining base in northern China, in addition to evaluating major factors that influence these metrics. 


\section{Study Area, Data Collection, and Methods}

\subsection{Study Area}

The upper Fenhe River is about $217.3 \mathrm{~km}$ in length, with the Lancun hydrological station at the terminus. The river basin covers about $7705 \mathrm{~km}^{2}$ within the Ningwu, Jingle, Lanxian, Loufan, and Yangqu counties, in addition to Gujiao city and the Jiancaoping District of Taiyuan city, which is the capital city of the Shanxi Province [29]. The area is characterized by a temperate continental monsoon climate. The annual precipitation varies from 213 to $798 \mathrm{~mm}$, more than $80 \%$ of which falls between June and September. The annual average temperature is $8.5-11.8^{\circ} \mathrm{C}$. The major topography of the basin is loess hilly-gully, rocky mountains, and riparian zone. Particularly, the loess hilly-gully area, which forms a severe erosion area in the basin with an average erosion modulus of 6700 ton $\cdot \mathrm{km}^{-2} \cdot \mathrm{a}^{-1}$, contributes about $70 \%$ of the erosion in the basin with less than $40 \%$ of the area [30]. The zonal vegetation is characterized as a temperate sub-humid deciduous broad-leaved forest [31]. The dominant plant species of the area include Quercus wutaishansea Mary, Pinus tabuliformis, Hippophae rhamnoides, and others. Agricultural cultivation was previously the primary source of economic income in the basin, where croplands accounted for more than $50 \%$ of the basin area at one point [32]. Following the implementation of China's reform and opening-up policy in 1978, coal mining industries began to dominate economies in Ningwu county, Lanxian county, Gujiao city, and Taiyuan city, with some croplands and forestlands being converted to construction lands. Construction lands substantially expanded after 2000 with the rapid development of the economy and urbanization across the whole basin [33]. Concomitantly, vegetation coverage increased in the basin due to the implementation of the national level "Soil and Water Conservation" program for 20 years, beginning in 1988. Further, the initiation of the "Natural Forest Protection" and "Grain for Green" programs in the late 1990s and 2003, respectively, particularly promoted the restoration of native environments [33,34].

Hydrological stations and rainfall gauge stations were established by the Chinese Water Conservancy Department on the main stream of the upper Fenhe River and its major tributaries (e.g., the Lanhe River, which is the largest tributary of the upper Fenhe River) in the 1950s to monitor variations in hydrological characteristics. The No. 1 and No. 2 Fenhe reservoirs are present on the main stream of the upper Fenhe River and were completed in 1961 and 2000, respectively. The reservoirs have capacities of $7.12 \times 10^{8}$ and $1.33 \times 10^{8} \mathrm{~m}^{3}$, respectively, and are used for flood protection, water supplies, and electricity. In addition, the Lancheng and Hamashen reservoirs were built on the Lanhe River tributary in 1973 and 1975, respectively, and feature storage capacities of $6.0 \times 10^{6}$ and $6.24 \times 10^{6} \mathrm{~m}^{3}$, respectively [29]. Furthermore, a large-scale, cross-basin water transfer project, the Yellow River Water Transfer Project, was initiated in October 2003, primarily to alleviate intensified water scarcities in Taiyuan city, and exhibits an annual water transfer capacity of 640 million $\mathrm{m}^{3}$. The project transfers water from the Wanjiazhai Reservoir of the Yellow River via tunnels, aqueducts, pipelines, and a section of the upper Fenhe River channel to the No. 1 Fenhe Reservoir. The waters then supplement the Taiyuan city water supplies via underground pipelines from the reservoir [35].

\subsection{Data and Methods}

Annual $\mathrm{Q}\left(\mathrm{Q}_{\mathrm{a}}\right)$ and $\mathrm{S}\left(\mathrm{S}_{\mathrm{a}}\right)$ data were collected from four hydrological stations in the upper Fenhe River Basin, representing the longest available time series (1955-2015) to investigate temporal variation in $Q_{a}$ and $S_{a}$ values over those 60 years. The four hydrological stations included three stations on the main stream of the upper Fenhe River (Jingle, Zhaishang, and Lancun; referred to as JL, ZS, and LC, respectively) and one station (Shangjingyou, SJY) at the terminus of the Lanhe River.

Annual precipitation $\left(\mathrm{P}_{\mathrm{a}}\right)$ data from the four hydrological stations, in addition to six other rainfall gauge stations (Dongzhai, Ninghuabao, Suopo, Puming, Miyu, and Chakou), from 1955 to 2015 were collected to explore the $\mathrm{Q}_{\mathrm{a}}$ and $\mathrm{S}_{\mathrm{a}}$ values for JL, SJY, ZS, and LC in response to changes in the average $\mathrm{P}_{\mathrm{a}}$ values $\left(\mathrm{P}_{\mathrm{ma}}\right)$ for individual catchments. All of the above data were collected from the Yellow River Water Conservancy Commission. The $\mathrm{P}_{\mathrm{ma}}$ values for the JL, SJY, ZS, and LC catchments (abbreviated 
as $\mathrm{P}_{\text {maJL }}$ for the JL catchment, for example) were calculated using the arithmetic mean of $\mathrm{P}_{\mathrm{a}}$ for stations and rainfall gauges that were located within the catchments.

The annual average air temperature data for the Taiyuan meteorological station $\left(\mathrm{T}_{\mathrm{TY}}\right)$ from 1955 to 2015 were only collected due to the lack of such long-term time-series data at other meteorological stations. The $\mathrm{T}_{\mathrm{TY}}$ data were collected from the Shanxi Meteorological Information Center to explore variations in $Q_{a}$ and $S_{a}$ values at the nearby $L C$ station in response to air temperature changes. Variations of $\mathrm{P}_{\mathrm{ma}}$ for JL, SJY, ZS, and LC catchments and $\mathrm{T}_{\mathrm{TY}}$ during the different periods are provided in Table 1. Additional details for the above stations are provided in Figure 1.

Table 1. Variations of the average annual precipitation at four catchments and the annual average air temperature at Taiyuan meteorological station for the different periods.

\begin{tabular}{|c|c|c|c|c|c|c|c|c|c|c|}
\hline \multirow[b]{2}{*}{ Periods } & \multicolumn{2}{|c|}{$P_{\text {maJL }}$} & \multicolumn{2}{|c|}{$P_{\text {maSJY }}$} & \multicolumn{2}{|c|}{$\mathbf{P}_{\mathrm{maZs}}$} & \multicolumn{2}{|c|}{$\mathbf{P}_{\mathrm{maLC}}$} & \multicolumn{2}{|c|}{$\mathbf{T}_{\mathrm{TY}}$} \\
\hline & $\begin{array}{l}\text { Mean } \\
(\mathrm{mm})\end{array}$ & $\begin{array}{l}\text { CV } \\
(\%)\end{array}$ & $\begin{array}{l}\text { Mean } \\
(\mathrm{mm})\end{array}$ & $\begin{array}{l}\text { CV } \\
(\%)\end{array}$ & $\begin{array}{l}\text { Mean } \\
(\mathrm{mm})\end{array}$ & $\begin{array}{l}\text { CV } \\
(\%)\end{array}$ & $\begin{array}{l}\text { Mean } \\
(\mathrm{mm})\end{array}$ & $\begin{array}{l}\text { CV } \\
(\%)\end{array}$ & $\begin{array}{l}\text { Mean } \\
(\mathrm{mm})\end{array}$ & $\begin{array}{l}\text { CV } \\
(\%)\end{array}$ \\
\hline 1955-1959 & 541 & 27.80 & 436 & 28.87 & 492 & 28.59 & 494 & 28.01 & 9.4 & 6.03 \\
\hline 1960-1969 & 529 & 30.25 & 484 & 27.61 & 509 & 27.79 & 510 & 27.43 & 9.5 & 5.31 \\
\hline 1970-1979 & 468 & 22.57 & 443 & 27.60 & 449 & 22.87 & 453 & 23.12 & 9.6 & 4.30 \\
\hline 1980-1989 & 432 & 17.60 & 424 & 30.51 & 437 & 21.92 & 437 & 22.27 & 9.7 & 3.95 \\
\hline 1990-1999 & 500 & 26.73 & 408 & 13.77 & 450 & 20.93 & 449 & 21.66 & 10.4 & 7.11 \\
\hline 2000-2009 & 515 & 19.60 & 469 & 24.16 & 488 & 19.58 & 487 & 19.78 & 11.0 & 3.72 \\
\hline 2010-2015 & 565 & 11.10 & 533 & 14.53 & 533 & 12.67 & 530 & 12.43 & 11.0 & 2.51 \\
\hline
\end{tabular}

Mean: arithmetic mean value of $P_{m a}$ during each period. CV: coefficient of variation of $P_{m a}$ during each period.

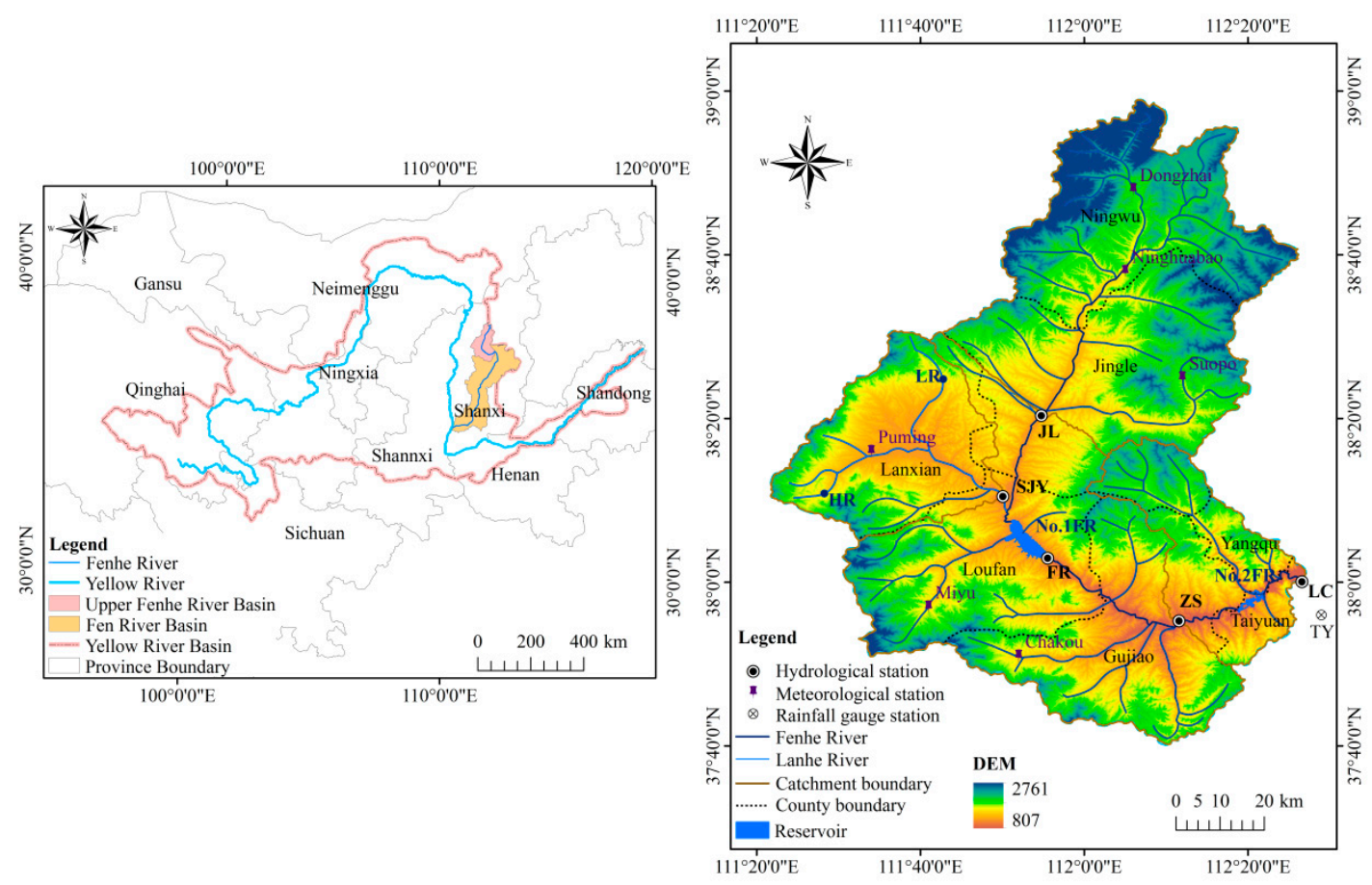

Figure 1. Location of the Upper Fenhe River Basin and details: No. 1 FR: No. 1 Fenhe Reservoir; No. 2 FR: No. 2 Fenhe Reservoir; LR: Lancheng Reservoir; HR: Hamashen Reservoir.

The $Q_{a}$ data for the No. 1 Fenhe Reservoir hydrological station (FR) $\left(Q_{\mathrm{aFR}}\right)$ at the outlet of the reservoir was collected for the years 1962-2015 from the Yellow River Water Conservancy Commission to explore $\mathrm{Q}_{\mathrm{azS}}$ and $\mathrm{Q}_{\mathrm{aLC}}$ changes in response to the construction of the No. 1 Fenhe Reservoir. Annual sediment deposition volume data for the No. 1 Fenhe Reservoir $\left(D_{a F R}\right)$ from 1963 to 2015 and cumulative sediment deposition volume from 1960 to 1962 were collected from the Fenhe Reservoir Administration Bureau to analyze the effect of the reservoir on $\mathrm{S}_{\mathrm{azS}}$ and $\mathrm{S}_{\mathrm{aLC}}$ variations. 
Monthly normalized difference vegetation index (NDVI) datasets, including the Global Inventory Modeling and Mapping Studies (GIMMS) NDVI3g dataset and the Terra Moderate Resolution Imaging Spectroradiometer (MODIS, NASA, Washington DC, USA) Vegetation Indices (MOD13Q1) dataset, were collected to analyze the relationships between vegetation coverage and $Q_{a}$ or $S_{a}$ values over the study period. The GIMMS NDVI3g dataset was derived from the NOAA/AVHRR land dataset at a spatial resolution of $8 \mathrm{~km}$ in 15-day intervals from 1982 to 2015. The MODIS MOD13Q1 dataset exhibited a $250 \mathrm{~m}$ spatial resolution at 16-day intervals from 2000 to 2015, and was derived from the Earth Observing System of NASA [36]. Monthly NDVI values for the two datasets were first obtained using the maximum value composite method, which minimizes cloud contamination, atmospheric effects, and solar zenith angle effects [37]. The yearly NDVI value of each pixel was then calculated by computing the maximum values for the 12 monthly NDVI values. Finally, the annual regional values of GIMMS NDVI (NDVI $8 \mathrm{~km}$ ) and MODIS NDVI (NDVI $250 \mathrm{~m})$ for the JL, SJY, ZS, and LC catchments were separately calculated by computing the average yearly NDVI values for all grid cells within those catchments. Additionally, the annual floor space data for buildings under construction in Taiyuan city $\left(\mathrm{FSBC}_{\mathrm{TY}}\right.$ ) were collected for the years from 1996 to 2015 from the Shanxi Province Statistical Yearbook [38] to better understand the use of sand excavation and explore the associated impacts on $S_{a}$.

Autocorrelation was evaluated for the calculated metrics before analyzing the monotonic trends of the $Q_{a}$ and $S_{a}$ time series for the JL, SJY, ZS, and LC stations, in addition to their respective $P_{m a}$, $\mathrm{NDVI}_{8 \mathrm{~km}}$, and $\mathrm{NDVI}_{250 \mathrm{~m}}$ values for the four respective catchments. Furthermore, autocorrelation was evaluated for the $T_{T Y}, Q_{a F R}$, and $D_{a F R}$ metrics [39]. The monotonic trends of the above variables were determined using nonparametric Mann-Kendall tests [40,41]. The magnitudes of the trends for the respective variables were indicated using Sen's slopes [42]. The inflection points of the variables were identified based on the separate intersection of $U_{F}$ and $U_{B}$ curves from the Mann-Kendall tests within the confidence interval of $[-0.01,0.01][43,44]$. In addition, abrupt inflection points for $Q_{a}$ and $S_{a}$ values for the four stations were detected from the variation in slope for straight lines that were fitted to double mass curves of $Q_{a}-P_{m a}$ and $S_{a}-P_{m a}$ [45]. The abrupt inflection points obtained using the double mass curve method were used as nodes to divide periods (see Section 3.3) and further investigate changes in $Q_{a}, S_{a}$, and the $Q_{a}-S_{a}$ relationships, in addition to their potential influential factors. The $Q_{a}-S_{a}$ relationships within different periods were analyzed using simple linear regression analyses. Linear regression models were tested using $\mathrm{F}$ tests to evaluate the statistical differences in relationships. Correlations between $Q_{a}$ or $S_{a}$ and influential indicators (i.e., $P_{m a}, N V_{18 m}, N V_{250 m}$, $\mathrm{T}_{\mathrm{TY}}, \mathrm{Q}_{\mathrm{aFR}}$, and $\mathrm{D}_{\mathrm{aFR}}$ ) were analyzed using Pearson correlation analysis.

\section{Results}

\subsection{Temporal Variation in $Q_{a}$ and $S_{a}$ Based on Mann-Kendall Tests}

The temporal variation in $Q_{a}$ and $S_{a}$ values for the JL, SJY, ZS, and LC stations from 1955 to 2015 is shown in Figure 2. The $Q_{a}$ variables, excluding $Q_{a J L}$, exhibited highly significant decreasing trends over the 60 years of the study, with average reduction rates of $0.68-1.07 \mathrm{~mm} \cdot \mathrm{km}^{-2} \cdot \mathrm{a}^{-1}(p<0.001)$ (Table 2). $S_{a}$ values for the above four stations also exhibited significant decreasing trends over the same period, with average reduction rates of $9.24-54.39 \mathrm{t} \cdot \mathrm{km}^{-2} \cdot \mathrm{a}^{-1}(p<0.001$ or $p<0.01)$. The most significant decreases in the $Q_{a}$ and $S_{a}$ rates were observed at LC and SJY, respectively. The inflection points for $Q_{a}$ were identified in 1983 for SJY, 1980 for ZS, and 1981 for LC, while the inflection points for $\mathrm{S}_{\mathrm{a}}$ occurred in 2004 for JL, 1997 for SJY, 1991 for ZS, and 1994 for LC (Figure 3). 

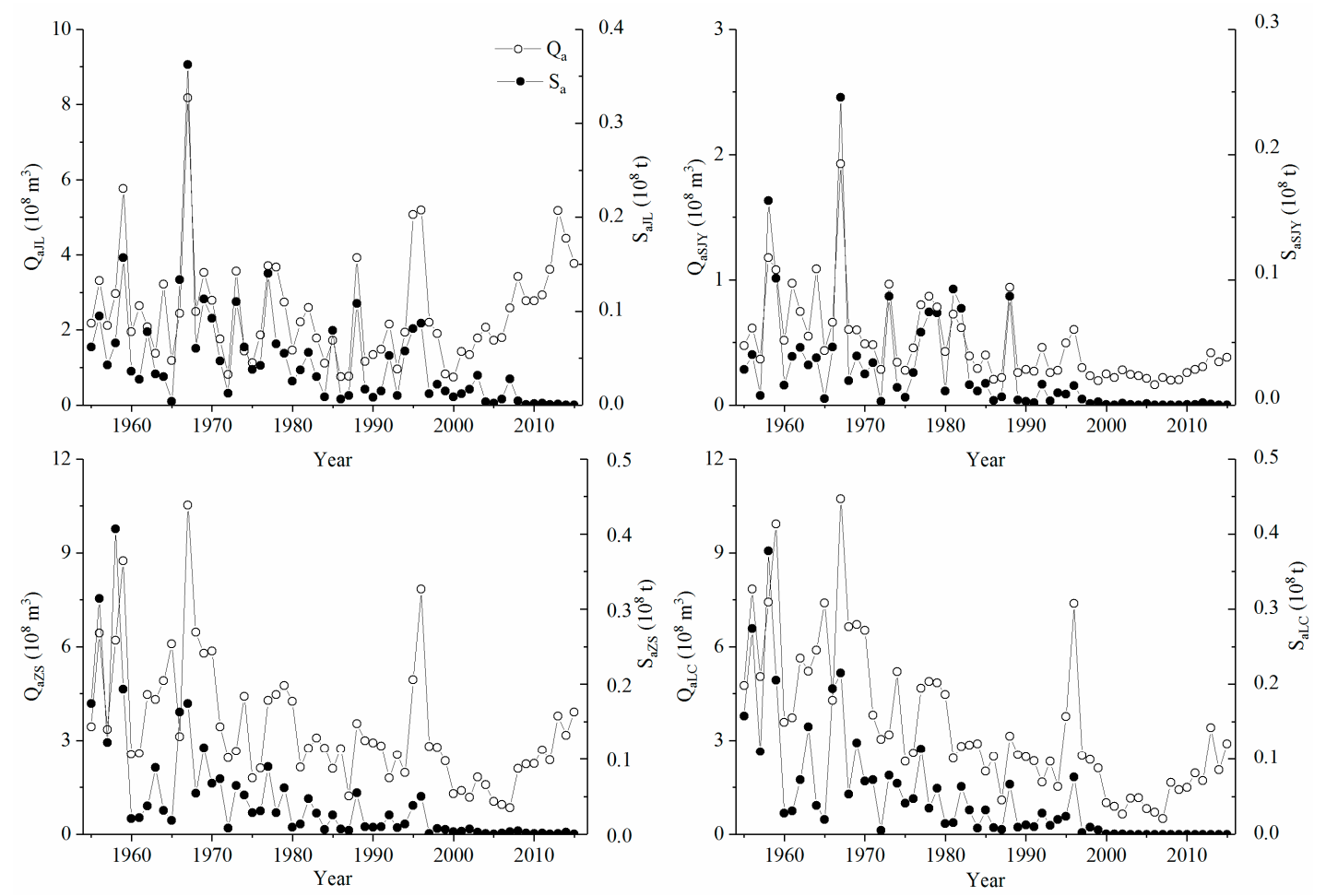

Figure 2. Temporal variation in $Q_{a}$ and $S_{a}$ values for four hydrological stations from 1955 to 2015. JL: Jingle, ZS: Zhaishang, LC: Lancun, SJY: Shangjingyou.
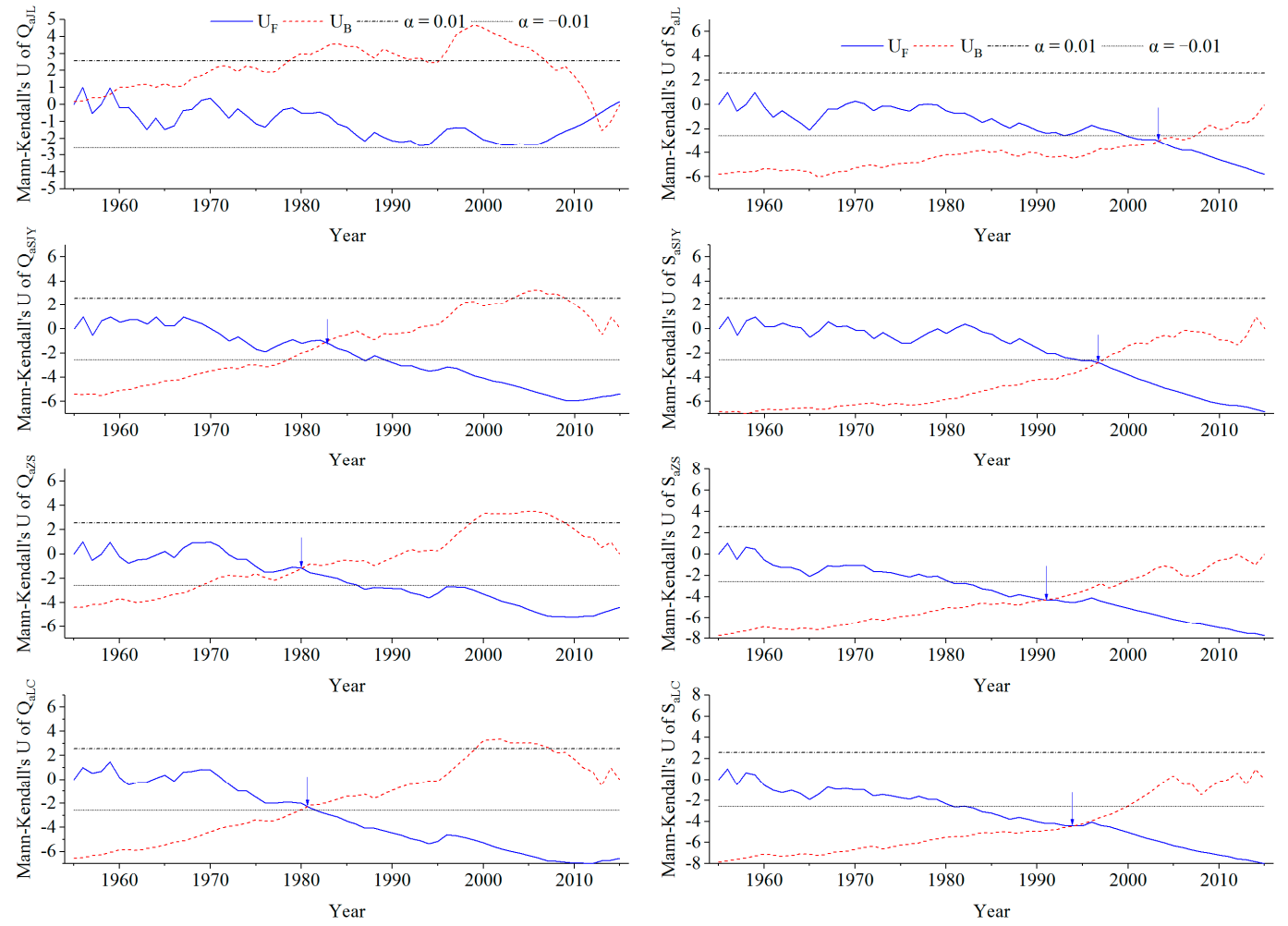

Figure 3. Mann-Kendall tests of the $Q_{a}$ and $S_{a}$ values for four hydrological stations from 1955 to 2015. The horizontal dashed lines represent the critical values corresponding to the $99 \%$ significance level. Solid blue arrow denotes inflection point years during the study period using Mann-Kendall tests. 
Table 2. $Q_{a}$ and $S_{a}$ trends revealed by the Mann-Kendall tests.

\begin{tabular}{|c|c|c|c|c|c|}
\hline \multirow[b]{2}{*}{ Stations } & \multirow[b]{2}{*}{$\begin{array}{l}\text { Controlling } \\
\text { Area }\left(\mathbf{k m}^{2}\right)\end{array}$} & \multicolumn{2}{|c|}{$Q_{a}(1955-2015)$} & \multicolumn{2}{|c|}{$S_{a}(1955-2015)$} \\
\hline & & $\mathbf{Z}$ & $\begin{array}{c}\beta \\
\left(\mathrm{mm} \cdot \mathrm{km}^{-2} \cdot \mathrm{a}^{-1}\right)\end{array}$ & $\mathbf{Z}$ & $\begin{array}{c}\beta \\
\left(\mathrm{t} \cdot \mathrm{km}^{-2} \cdot \mathrm{a}^{-1}\right)\end{array}$ \\
\hline $\mathrm{JL}$ & 2799 & $0.86^{\mathrm{ns}}$ & 0.41 & $-4.89^{* * *}$ & -34.66 \\
\hline SJY & 1140 & $-5.05^{* * *}$ & -0.68 & $-3.17^{* *}$ & -54.39 \\
\hline ZS & 6819 & $-3.34^{* * *}$ & -0.73 & $-2.62 * *$ & -9.24 \\
\hline $\mathrm{LC}$ & 7705 & $-5.56^{* * *}$ & -1.07 & $-3.72 * * *$ & -14.8 \\
\hline
\end{tabular}

$Z: Z$ value from the Mann-Kendall tests; $\beta$ : Sen's slope represents the average change rate; ns: no significant change; *** significant at $p<0.01 ; * * *$ significant at $p<0.001$.

\subsection{Temporal Variation of $Q_{a}-P_{m a}$ and $S_{a}-P_{m a}$ Based on Double Mass Curves}

Cumulative $Q_{a}$ and $S_{a}$ values were plotted against cumulative $P_{m a}$ values for the four stations (Figure 4). Except for the double mass curve of $\mathrm{Q}_{\mathrm{aJL}}-\mathrm{P}_{\mathrm{maJL}}$, which manifested as a straight line without segmentation, the other double mass curves for $\mathrm{S}_{\mathrm{aJL}}-\mathrm{P}_{\mathrm{maJL}}, \mathrm{Q}_{\mathrm{aSJY}}-\mathrm{P}_{\mathrm{maSJY}}$, and $\mathrm{S}_{\mathrm{aSJY}}-\mathrm{P}_{\mathrm{maSJY}}$ unanimously trended rightwards with abrupt inflection points occurring in 1982 and 1996. The double mass curves of $Q_{a}-P_{m a}$ and $S_{a}-P_{m a}$ for $Z S$ and LC, respectively, varied nearly synchronously, with the same abrupt inflection points occurring in 1980 and 1996, respectively, in the cumulative $Q_{a}-P_{m a}$ curves and for the cumulative $S_{a}-P_{m a}$ curves in 1959, 1980, and 1996.
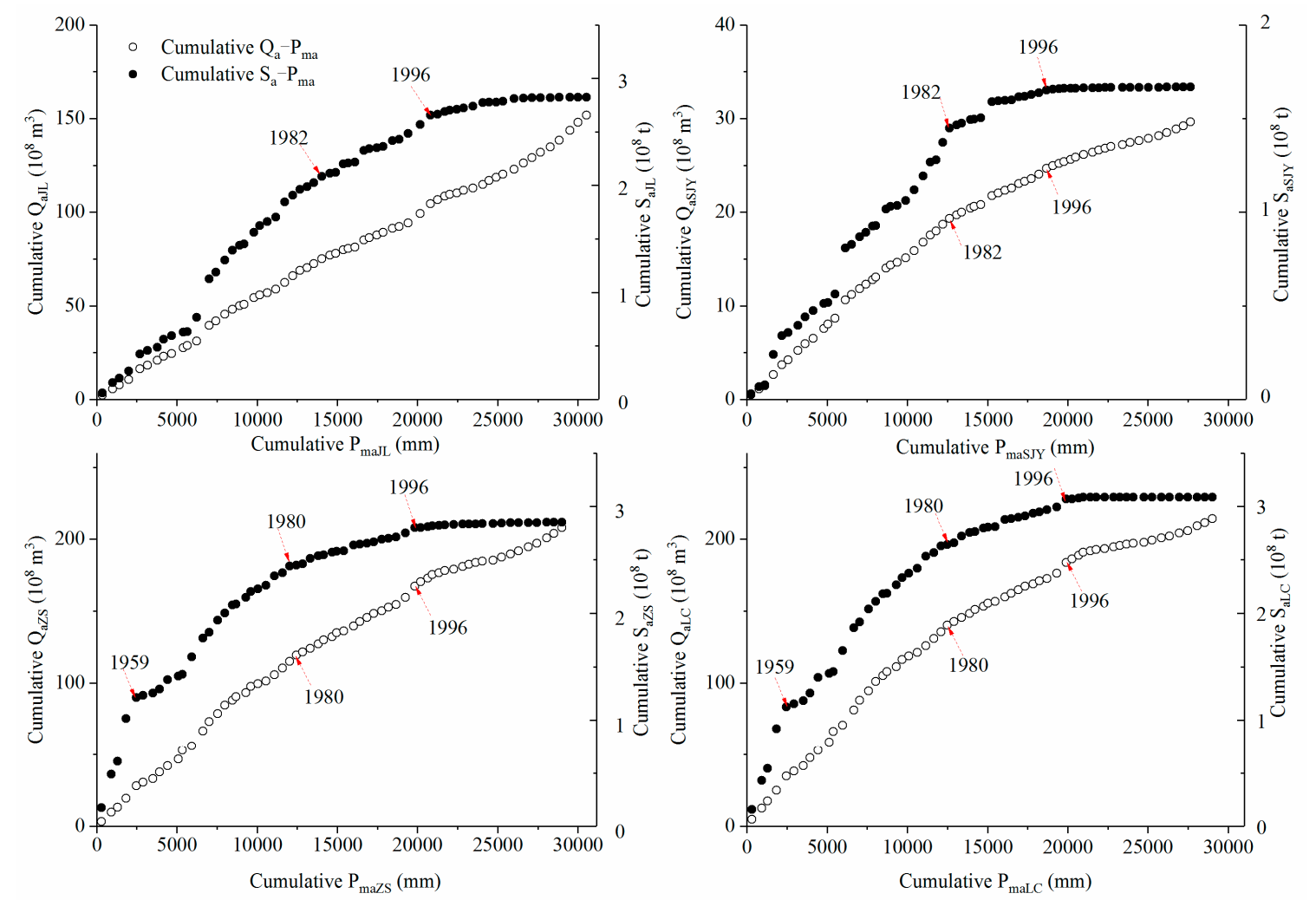

Figure 4. Double-mass curves of $Q_{a}-P_{m a}$ and $S_{a}-P_{m a}$ for four hydrological stations from 1955 to 2015.

Dotted red arrows denote inflection point years during the study period using double mass curves.

\subsection{Changes in Average $Q_{a}, S_{a}$, and the $Q_{a}-S_{a}$ Relationships during Three Separate Study Periods}

Three periods were used to investigate changes in the $Q_{a}, S_{a}$, and the $Q_{a}-S_{a}$ relationships, with 1982 and 1996 as the nodes of $Q_{a S J Y}$ and $S_{a S J Y}$, and 1980 and 1996 as the nodes of $Q_{a}$ and $S_{a}$ for ZS and LC. To facilitate comparisons among the four stations, the $\mathrm{Q}_{\mathrm{aJL}}$ and $\mathrm{S}_{\mathrm{aJL}}$ series were divided into three periods, with 1982 and 1996 as the nodes. Specifically, the three periods for $Q_{a}$ and $S_{a}$ values of JL and 
SJY were defined as 1955-1982 (period I), 1983-1996 (period II), and 1997-2015 (period III). Likewise, the three periods for $Q_{a}$ and $S_{a}$ values for ZS and LC were defined as 1955-1980 (period I), 1981-1996 (period II), and 1997-2015 (period III). The reductions in average $Q_{a}$ for the four stations during periods II and III compared to period I were $21.77-49.46 \%$ and $7.25-70.35 \%$, respectively (Table 3). The level of reduction in the average $S_{a}$ was greater than that of $Q_{a}$ for the four stations, with average $S_{a}$ values decreasing in periods II and III by $45.03-76.62 \%$ and $88.08-99.04 \%$, respectively, when compared to period I.

The $\mathrm{Q}_{\mathrm{a}}-\mathrm{S}_{\mathrm{a}}$ relationships for JL, SJY, ZS, and LC during the three periods are shown in Figure 5. The simple linear regression lines, equations, and determination coefficients $\left(R^{2}\right)$ for all relationships are presented simultaneously for ease of interpretation, although some were not statistically significant. The $Q_{a}-S_{a}$ relationships for the four stations during periods I and II fit linear functions well, as indicated by the significant $\mathrm{R}^{2}$ values $(p<0.01)$. All of the regression lines for period II were below those of period I, indicating that the value of $S_{a}$ decreased given the same values of $Q_{a}$ under such conditions. The slope of the $\mathrm{Q}_{\mathrm{aJL}}-\mathrm{S}_{\mathrm{aJL}}$ relationship regression line was negative during period III, contrasting with the positive slopes observed during the first two periods. Extremely low $\mathrm{R}^{2}$ values observed for SJY, $\mathrm{ZS}$, and LC regressions during period III indicated the lack of significant correlations between $\mathrm{Q}_{\mathrm{a}}$ and $\mathrm{S}_{\mathrm{a}}$ values for the three stations during this period.
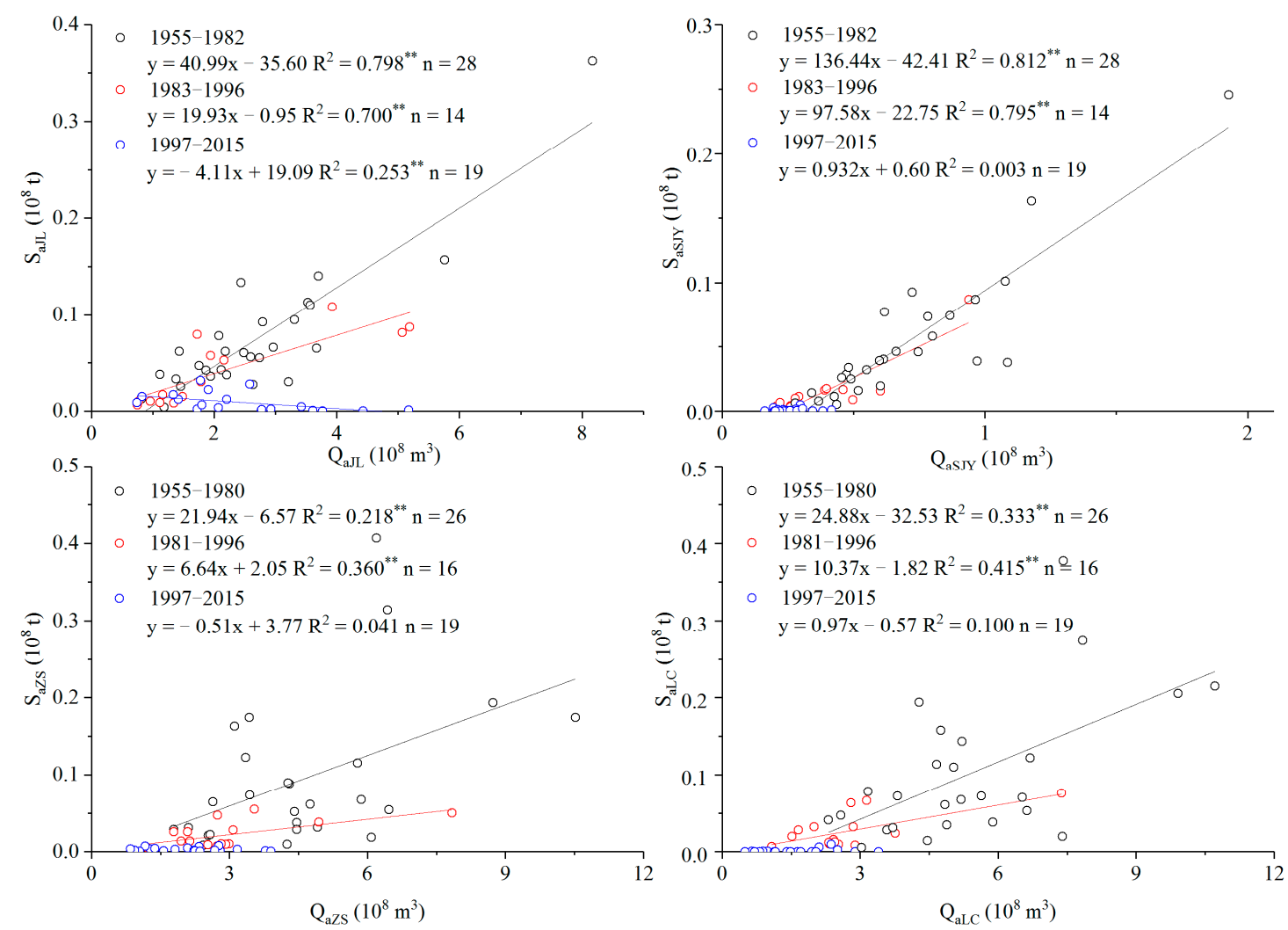

Figure 5. Scatterplot distributions and regression equations for the $Q_{a}-S_{a}$ relationships for the four stations. ${ }^{* *}$ Significant at $p<0.01$. 
Table 3. Changes in average $\mathrm{Q}_{\mathrm{a}}$ and $\mathrm{S}_{\mathrm{a}}$ values during different periods.

\begin{tabular}{|c|c|c|c|c|c|}
\hline \multirow{2}{*}{ Variable } & \multirow{2}{*}{$\frac{1955-1982(\text { Period I })}{\text { Mean }\left(10^{8} \mathrm{~m}^{3}\right)}$} & \multicolumn{2}{|c|}{ 1983-1996 (Period II) } & \multicolumn{2}{|c|}{ 1997-2015 (Period III) } \\
\hline & & Mean $\left(10^{8} \mathrm{~m}^{3}\right)$ & Change Rate (\%) & Mean $\left(10^{8} \mathrm{~m}^{3}\right)$ & Change Rate (\%) \\
\hline $\mathrm{Q}_{\mathrm{aJL}}$ & 2.68 & 2.10 & -21.77 & 2.49 & -7.25 \\
\hline $\mathrm{Q}_{\mathrm{aSJY}}$ & 0.69 & 0.38 & -44.53 & 0.26 & -62.29 \\
\hline \multirow{2}{*}{ Variable } & 1955-1982 (Period I) & \multicolumn{2}{|c|}{ 1983-1996 (Period II) } & \multicolumn{2}{|c|}{ 1997-2015 (Period III) } \\
\hline & Mean $\left(10^{5} t\right)$ & Mean $\left(10^{5} t\right)$ & Change Rate (\%) & Mean $\left(10^{5} t\right)$ & Change Rate (\%) \\
\hline $\mathrm{S}_{\mathrm{aJL}}$ & 74.37 & 40.88 & -45.03 & 8.87 & -88.08 \\
\hline $\mathrm{S}_{\mathrm{aSJY}}$ & 51.73 & 14.59 & -71.79 & 0.85 & -98.36 \\
\hline \multirow{2}{*}{ Variable } & 1955-1980 (Period I) & \multicolumn{2}{|c|}{ 1981-1996 (Period II) } & \multicolumn{2}{|c|}{ 1997-2015 (Period III) } \\
\hline & Mean $\left(10^{8} \mathrm{~m}^{3}\right)$ & Mean $\left(10^{8} \mathrm{~m}^{3}\right)$ & Change Rate (\%) & Mean $\left(10^{8} \mathrm{~m}^{3}\right)$ & Change Rate (\%) \\
\hline $\mathrm{Q}_{\mathrm{aZS}}$ & 4.59 & 3.01 & -34.55 & 2.13 & -53.65 \\
\hline $\mathrm{Q}_{\mathrm{aLC}}$ & 5.39 & 2.73 & -49.46 & 1.60 & -70.35 \\
\hline \multirow{2}{*}{ Variable } & 1955-1980 (Period I) & \multicolumn{2}{|c|}{ 1981-1996 (Period II) } & \multicolumn{2}{|c|}{ 1997-2015 (Period III) } \\
\hline & Mean $\left(10^{5} t\right)$ & Mean $\left(10^{5} t\right)$ & Change Rate (\%) & Mean $\left(10^{5} t\right)$ & Change Rate (\%) \\
\hline $\mathrm{S}_{\mathrm{aZS}}$ & 94.20 & 22.02 & -76.62 & 2.69 & -97.14 \\
\hline $\mathrm{S}_{\mathrm{aLC}}$ & 101.66 & 26.45 & -73.99 & 0.98 & -99.04 \\
\hline
\end{tabular}

Mean: arithmetic mean value of $Q_{a}$ or $S_{a}$ during each period. Change rate: change rate of the mean value of $Q_{a}$ or $\mathrm{S}_{\mathrm{a}}$ in periods II or III compared with that in period I.

\subsection{Temporal Variation in Potential Influential Variables}

Trend-based analyses were conducted for representative environmental indicators in the study area, including $\mathrm{P}_{\mathrm{ma}}, \mathrm{NDVI}_{8 \mathrm{~km}}$, and $\mathrm{NDVI}_{250 \mathrm{~m}}$ metrics for the four catchments, in addition to the other environmental metrics $\mathrm{T}_{\mathrm{TY}}, \mathrm{Q}_{\mathrm{aFR}}$, and $\mathrm{D}_{\mathrm{aFR}}$. Significant changes were not observed for $\mathrm{P}_{\mathrm{maJL}}, \mathrm{P}_{\mathrm{maSJY}}$, $\mathrm{P}_{\text {maZS, }}$ and $\mathrm{P}_{\mathrm{maLC}}$ from 1955 to 2015 (Table 4). However, average $\mathrm{P}_{\text {maJL }}, \mathrm{P}_{\text {maSJY }}, \mathrm{P}_{\text {maZs, }}$ and $\mathrm{P}_{\mathrm{maLC}}$ values for period II $(484.2,432.5,462.5$, and $462.5 \mathrm{~mm}$, respectively) were lower than those of period I (501.0, 450.8, 475.7, and $477.8 \mathrm{~mm}$, respectively) and period III (512.0, 472.0, 481.6, and $480.0 \mathrm{~mm}$, respectively) (Figure 6a). A significant increase in $\mathrm{T}_{\mathrm{TY}}$ values was observed from 1955 to 2015 with an average increasing rate of $0.36^{\circ} \mathrm{C}(10 \mathrm{a})^{-1}(\mathrm{Z}=5.31, p<0.001)$. Moreover, average $\mathrm{T}_{\mathrm{TY}}$ values for period III were clearly higher than those for the first two periods (Figure $6 \mathrm{~b}$ ). In contrast, a significant decrease was observed for $Q_{\mathrm{aFR}}$ values from 1962 to $2015\left(\mathrm{Z}=-2.75, p<0.01 ; \beta=-7.80 \times 10^{6} \mathrm{~m}^{3} \cdot \mathrm{a}^{-1}\right)$ and for $\mathrm{D}_{\mathrm{aFR}}$ from 1963 to $2015\left(\mathrm{Z}=-3.75, p<0.001, \beta=-0.18 \times 10^{6} \mathrm{~m}^{3} \cdot \mathrm{a}^{-1}\right)$. The abrupt inflection points for the cumulative $Q_{a F R}$ curve occurred in 1980 and 1996, respectively, while those of the cumulative $D_{a F R}$ curve occurred in 1982 and 1996, respectively (Figure 7a). The NDVI $8 \mathrm{~km}$ values significantly increased from 1982 to 2015 in the four catchments $(p<0.05$ or $p<0.01$ or $p<0.001$ ) (Table 4 ), with rapid increases after 2000 that were consistent with the variations in $\mathrm{NDVI}_{250 \mathrm{~m}}$ during the 2000-2015 period $(p<0.001)$ (Figure 7b).

Table 4. Trends in influential variables revealed by the Mann-Kendall tests.

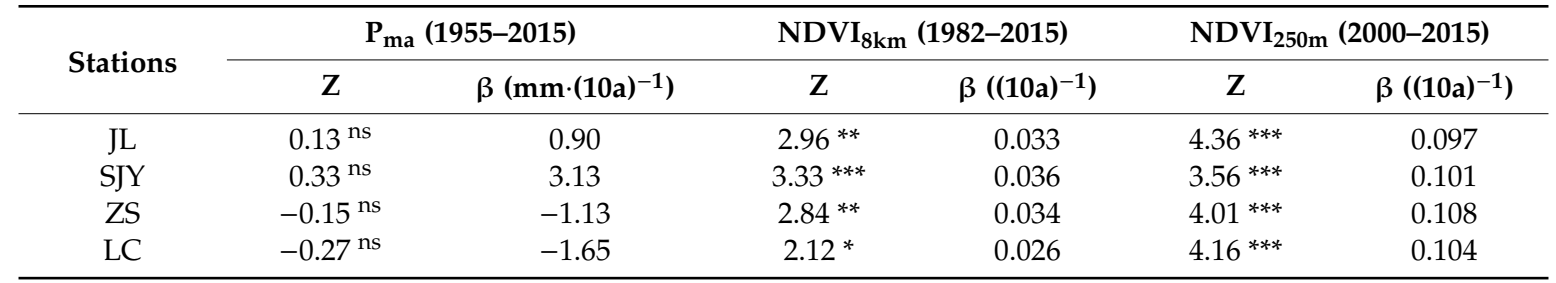

$\mathrm{Z}: \mathrm{Z}$ value from the Mann-Kendall tests; $\beta$ : Sen's slope represents the average change rate; ns: no significant change; * significant at $p<0.05 ;{ }^{* *}$ significant at $p<0.01 ;{ }^{* * *}$ significant at $p<0.001$. 


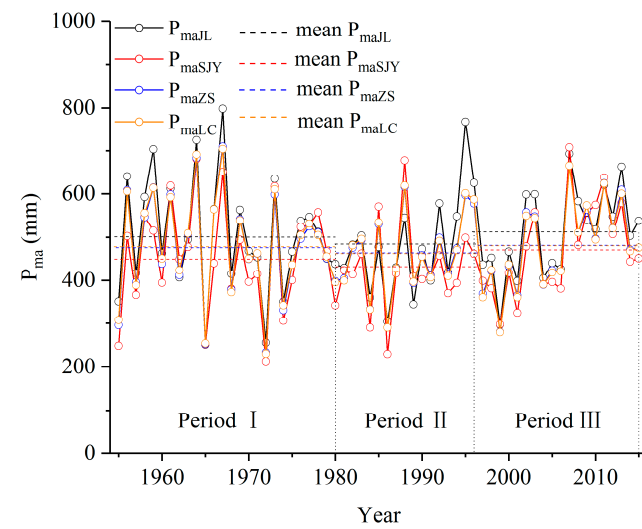

(a)

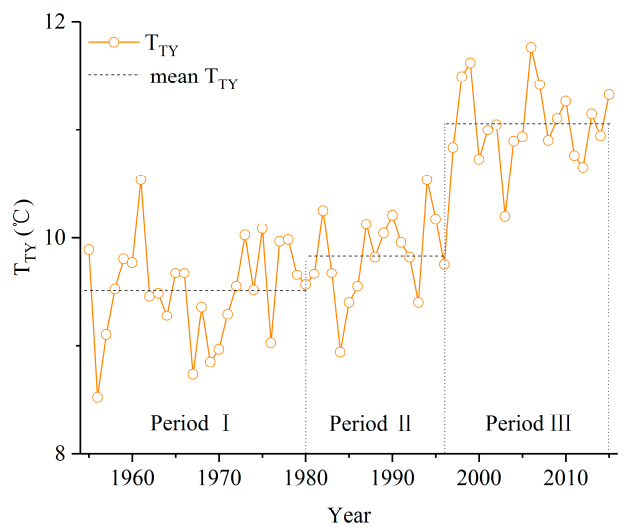

(b)

Figure 6. Temporal variation in (a) $\mathrm{P}_{\mathrm{maJL}}, \mathrm{P}_{\mathrm{maSJY}}, \mathrm{P}_{\mathrm{maZS}}$, and $\mathrm{P}_{\mathrm{maLC}}$ from 1955 to 2015; (b) $\mathrm{T}_{\mathrm{TY}}$ from 1955 to 2015.

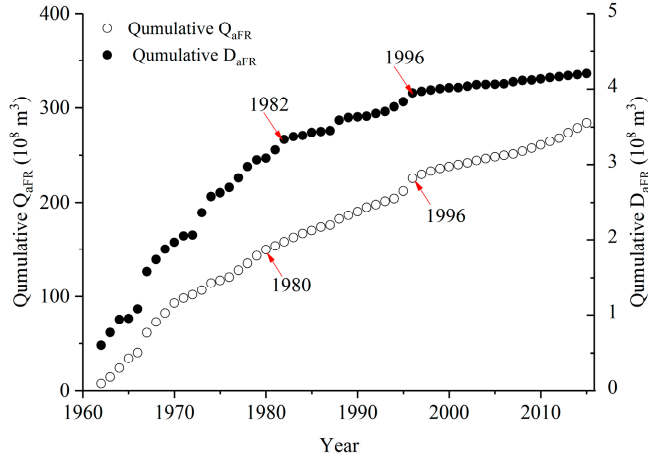

(a)

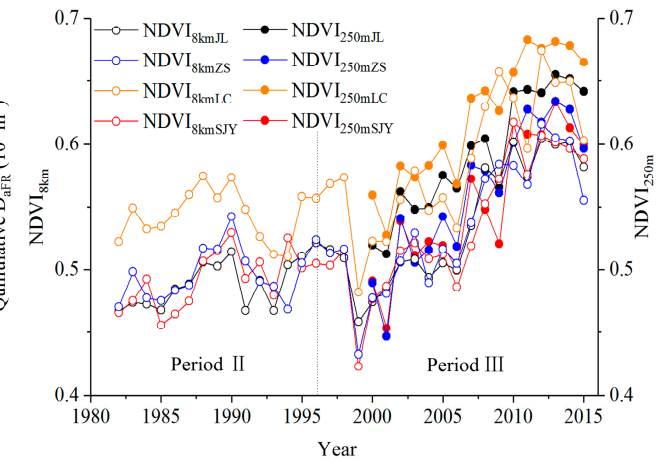

(b)

Figure 7. Temporal variation in (a) cumulative $Q_{\mathrm{aFR}}$ from 1962 to 2015 and $\mathrm{D}_{\mathrm{aFR}}$ from 1960 to 2015; (b) $\mathrm{NDVI}_{8 \mathrm{~km}}$ from 1982 to 2015 and NDVI $250 \mathrm{~m}$ from 2000 to 2015.

\subsection{Pearson's Correlations between $Q_{a}, S_{a}$, and Potential Influencing Variables}

The Pearson's correlation coefficients among $Q_{a}, S_{a}$, and the potential influential factors for the JL, SJY, ZS, and LC stations were investigated for different periods (Table 5). Significant and positive correlations were observed between $Q_{a}$ and $S_{a}$ values for the four stations over the first two periods $(p<0.01$ or $p<0.05)$. In contrast, significant negative correlations for $\mathrm{Q}_{\mathrm{aJL}}-\mathrm{S}_{\mathrm{aJL}}(p<0.05)$ and no significant correlations in the $\mathrm{Q}_{\mathrm{a}}-\mathrm{S}_{\mathrm{a}}$ relationships for the SJY, ZS, and LC stations were observed during period III. Significant and positive correlations were observed for the $\mathrm{Q}_{\mathrm{a}}-\mathrm{P}_{\mathrm{ma}}$ values of JL during the three periods $(p<0.01$ or $p<0.05)$ and for SJY during the first two periods $(p<0.01)$. In contrast, significant correlations were not observed for $\mathrm{Q}_{\mathrm{azS}}-\mathrm{P}_{\mathrm{maZs}}$ and $\mathrm{Q}_{\mathrm{aLC}}-\mathrm{P}_{\mathrm{maLC}}$ during the three periods. Significant positive correlations were observed for the $S_{a}-P_{m a}$ values of the four stations during the first two periods $(p<0.01$ or $p<0.05)$, except for $S_{a z S}-P_{\text {mazs }}$ during period I. Strongly positive and significant correlations were observed between $Q_{a}$ for the four stations and $Q_{a F R}$ during the three periods $\left(p<0.01\right.$ or $p<0.05$ ). Likewise, significant positive correlations were also observed for $\mathrm{S}_{\mathrm{a}}-\mathrm{D}_{\mathrm{aFR}}$ values of the four stations during the first two periods $(p<0.01)$. Significant positive correlations were observed for $\mathrm{Q}_{\mathrm{a}}-\mathrm{NDVI}_{8 \mathrm{~km}}$ for the JL and ZS stations during period II $(p<0.05)$. Likewise, significant positive correlations were observed for JL, SJY, and ZS during period III $(p<0.01$ or $p<0.05)$, in addition to similar relationships for $\mathrm{Q}_{\mathrm{a}}-\mathrm{NDVI}_{250 \mathrm{~m}}$ for all four stations during period III $(p<0.01)$. In contrast, significant negative correlations were observed for $\mathrm{S}_{\mathrm{a}}-\mathrm{NDVI}_{8 \mathrm{~km}}$ values of JL and $\mathrm{ZS}$, and for $\mathrm{S}_{\mathrm{a}}-\mathrm{NDVI}_{250 \mathrm{~m}}$ of LC over the same period $(p<0.05)$. 
Table 5. Pearson's correlations between $Q_{a}, S_{a}$, and potential influential variables.

\begin{tabular}{|c|c|c|c|c|c|c|c|c|c|c|c|c|c|c|c|c|c|c|c|c|c|c|c|c|}
\hline \multirow{4}{*}{ Correlation } & \multicolumn{6}{|c|}{$\mathrm{JL}$} & \multicolumn{6}{|c|}{ SJY } & \multicolumn{6}{|c|}{ zS } & \multicolumn{6}{|c|}{ LC } \\
\hline & \multirow{2}{*}{\multicolumn{2}{|c|}{$\begin{array}{c}\text { Period I } \\
1955-1982\end{array}$}} & \multirow{2}{*}{\multicolumn{2}{|c|}{\begin{tabular}{|c|} 
Period II \\
$1983-1996$
\end{tabular}}} & \multicolumn{2}{|c|}{ Period III } & \multicolumn{2}{|c|}{ Period I } & \multicolumn{2}{|c|}{ Period II } & \multicolumn{2}{|c|}{ Period III } & \multirow{2}{*}{\multicolumn{2}{|c|}{$\begin{array}{c}\text { Period I } \\
1955-1980\end{array}$}} & \multirow{2}{*}{\multicolumn{2}{|c|}{\begin{tabular}{|c|} 
Period II \\
$1981-1996$
\end{tabular}}} & \multirow{2}{*}{\multicolumn{2}{|c|}{\begin{tabular}{|l} 
Period III \\
$1997-2015$
\end{tabular}}} & \multirow{2}{*}{\multicolumn{2}{|c|}{$\begin{array}{l}\text { Period I } \\
1955-1980\end{array}$}} & \multirow{2}{*}{\multicolumn{2}{|c|}{\begin{tabular}{|c|} 
Period II \\
$1981-1996$
\end{tabular}}} & \multicolumn{2}{|c|}{ Period III } \\
\hline & & & & & & & & & & & & & & & & & & & & & & & & \\
\hline & $r$ & $\mathrm{n}$ & $r$ & $\mathrm{n}$ & $r$ & $\mathrm{n}$ & $r$ & $\mathrm{n}$ & $r$ & $\mathrm{n}$ & $r$ & $\mathrm{n}$ & $r$ & $\mathrm{n}$ & $r$ & $\mathrm{n}$ & $r$ & $\mathrm{n}$ & $r$ & $\mathrm{n}$ & $r$ & $\mathrm{n}$ & $r$ & $\mathbf{n}$ \\
\hline $\mathrm{Q}_{\mathrm{a}}-\mathrm{P}_{\mathrm{ma}}$ & $\star$ & 28 & $\star$ & 14 & $\bullet$ & 19 & $\star$ & 28 & $\star$ & 14 & ns & 19 & ns & 26 & ns & 16 & ns & 19 & ns & 26 & ns & 16 & ns & 19 \\
\hline $\mathrm{Q}_{\mathrm{a}}-\mathrm{Q}_{\mathrm{aFR}}$ & $\star$ & 21 & $\star$ & 14 & $\star$ & 19 & $\star$ & 21 & $\bullet$ & 14 & $\star$ & 19 & $\star$ & 21 & $\star$ & 16 & $\star$ & 19 & $\star$ & 21 & $\star$ & 16 & $\star$ & 19 \\
\hline $\mathrm{Q}_{\mathrm{a}}-\mathrm{D}_{\mathrm{aFR}}$ & $\star$ & 20 & $\star$ & 14 & ns & 19 & $\star$ & 20 & $\star$ & 14 & ns & 19 & $\star$ & 20 & ns & 16 & ns & 19 & $\bullet$ & 20 & ns & 16 & ns & 19 \\
\hline $\mathrm{Q}_{\mathrm{a}}-\mathrm{NDVI}_{8 \mathrm{~km}}$ & - & - & - & 14 & $\star$ & 19 & - & - & ns & 14 & $\star$ & 19 & - & - & $\bullet$ & 15 & 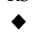 & 19 & - & - & ns & 15 & ns & 19 \\
\hline $\mathrm{Q}_{\mathrm{a}}-\mathrm{NDVI}_{250 \mathrm{~m}}$ & - & - & - & - & $\hat{\star}$ & 16 & - & - & - & - & $\hat{\star}$ & 16 & - & - & - & - & $\star$ & 16 & - & - & - & - & $\star$ & 16 \\
\hline $\mathrm{Q}_{\mathrm{a}}-\mathrm{S}_{\mathrm{a}}$ & $\star$ & 28 & $\star$ & 14 & $\hat{\diamond}$ & 19 & $\star$ & 28 & $\star$ & 14 & $\hat{\mathrm{ns}}$ & 19 & - & 26 & - & 16 & ns & 19 & $\star$ & 26 & $\star$ & 16 & ns & 19 \\
\hline $\mathrm{S}_{\mathrm{a}}-\mathrm{P}_{\mathrm{ma}}$ & $\star$ & 28 & $\star$ & 14 & ns & 19 & $\star$ & 28 & $\star$ & 14 & ns & 19 & ns & 26 & $\star$ & 16 & ns & 19 & $\bullet$ & 26 & $\star$ & 16 & ns & 19 \\
\hline $\mathrm{S}_{\mathrm{a}}-\mathrm{Q}_{\mathrm{aFR}}$ & $\star$ & 21 & $\bullet$ & 14 & $\diamond$ & 19 & $\star$ & 21 & ns & 14 & ns & 19 & $\star$ & 21 & $\star$ & 16 & ns & 19 & $\bullet$ & 21 & $\star$ & 16 & ns & 19 \\
\hline $\mathrm{S}_{\mathrm{a}}-\mathrm{D}_{\mathrm{a} F \mathrm{R}}$ & $\star \star$ & 20 & $\star$ & 14 & - & 19 & $\hat{\star}$ & 20 & $\star$ & 14 & ns & 19 & $\hat{\star}$ & 20 & $\hat{\star}$ & 16 & ns & 19 & $\star$ & 20 & $\hat{\star}$ & 16 & ns & 19 \\
\hline $\mathrm{S}_{\mathrm{a}}-\mathrm{NDVI}_{8 \mathrm{~km}}$ & - & - & ns & 14 & $\diamond$ & 19 & - & - & ns & 14 & ns & 19 & - & - & ns & 15 & $\diamond$ & 19 & - & - & ns & 15 & ns & 19 \\
\hline$Y \mathrm{~S}_{\mathrm{a}}-\mathrm{NDVI}_{250 \mathrm{~m}}$ & - & - & - & - & ns & 16 & - & - & - & - & ns & 16 & - & - & - & - & ns & 16 & - & - & - & - & $\diamond$ & 16 \\
\hline
\end{tabular}

$r$ : Pearson's correlation coefficients; n: number of variables; $\star$ : distinctly significant positive correlation $(p<0.01)$; $\bullet$ significant positive correlation $(p<0.05)$; $\diamond:$ significant negative correlation $(p<0.05)$; ns: no significant correlation; -: data is unavailable. 


\section{Discussion}

The Mann-Kendall tests indicated that the $Q_{a}$ values for the SJY, ZS, and LC stations dramatically decreased, beginning in the early 1980s (Table 2 and Figure 3). This was further evinced from obvious rightward shifts of the double mass curves for $Q_{a}-P_{m a}$ for the three stations around 1980 (Figure 4). A similar result was obtained by Zhang et al. [44] for the $Q_{a}$ series of the Fenhe River from 1957 to 2010. Average $\mathrm{P}_{\text {maSJY }}$ values during period II were lower than those of period I (Figure 6a), and significant positive correlations were observed for $\mathrm{Q}_{\mathrm{aSJY}}-\mathrm{P}_{\text {maSJY }}$ during the two periods $(p<0.01)$ (Table 5),

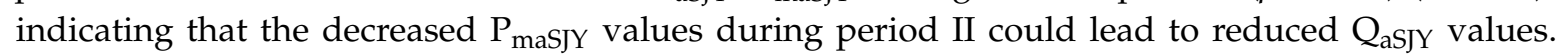
Similarly, significant correlations in the $S_{a S J Y}-P_{\text {maSJY }}$ and $\mathrm{Q}_{a S J Y}-S_{a S J Y}$ relationships $(p<0.01)$ indicated that decreased $P_{\text {maSJY }}$ and $Q_{a S J Y}$ during period II could have weakened sediment generation and carrying capacity, further reducing $S_{\mathrm{aSJY}}$. In addition to rainfall, other factors affected $\mathrm{Q}_{\mathrm{aSJY}}$ and $\mathrm{S}_{\mathrm{aSJY}}$ during period II, as indicated by the obvious rightward deflection of the cumulative $\mathrm{Q}_{\mathrm{aSJY}}-\mathrm{P}_{\text {maSJY }}$ and $\mathrm{S}_{\mathrm{aSJY}}-\mathrm{P}_{\text {maSJY }}$ curves around 1982. Qin [34] reported that the large-scale "Soil and Water Conservation" program was carried out in the upper Fenhe River Basin after 1988. Niu and Niu [46] further confirmed that 39 new check dams were built in the SJY catchment between 1983 and 1994, 33 of which were built after 1988, while only two reservoirs (the Lancheng and Hamashen reservoirs) and three check dams were built during period I. These check dams and reservoirs cumulatively controlled $50 \%$ of the drainage area in the loess hilly-gully areas of the SJY catchment, thereby effectively intercepting runoff and sediment, and dramatically reducing $\mathrm{Q}_{\mathrm{aSJY}}$ and $\mathrm{S}_{\mathrm{aSJY}}$ during period II. The reduced rainfall and increased soil and water conservation measures were also responsible for the decreased $Q_{a J L}$ and $S_{a J L}$ values observed for the same period. The $Q_{a J L}$ and $S_{a J L}$ values had comparatively lower decreases than $\mathrm{Q}_{\mathrm{aSJY}}$ and $\mathrm{S}_{\mathrm{aSJY}}$ during period II, respectively, when compared with the values for period I (Table 3). These differences may be related to different topographies among the two catchments. The SJY catchment is dominated by loess hilly-gully features that are more prone to soil erosion and more affected by soil and water conservation measures. In addition, the construction of two reservoirs in the SJY catchment could have also contributed to these observed differences.

Minimal $P_{\text {ma }}$ metric values were also observed for the ZS and LC catchments in the 1980s (Table 1 and Figure 6a), when the "Soil and Water Conservation" program was conducted in the two catchments after 1988. However, in contrast to the significant correlations in the $Q_{a S J Y}-P_{\text {maSJY }}$ and $Q_{a J L}-P_{m a J L}$ relationships observed during periods I and II $(p<0.01)$, significant correlations in the $Q_{a z s}-P_{\text {mazs }}$ and $\mathrm{Q}_{\mathrm{aLC}}-\mathrm{P}_{\text {maLC }}$ relationships were not observed during the two periods. Likewise, significant correlations were not observed for the $S_{a z s}-P_{\text {mazs }}$ relationships during period I. These observations could be attributed to the regulation of runoff and sediment-intercepting effects of the No. 1 Fenhe Reservoir that is upstream of ZS. This supposition is supported by significant correlations in the $\mathrm{Q}_{\mathrm{aZS}}-\mathrm{Q}_{\mathrm{aFR}}$ and $\mathrm{Q}_{\mathrm{aLC}}-\mathrm{Q}_{\mathrm{aFR}}$ relationships during the three periods $(p<0.01)$, as well as the synchronous appearance of the first inflection points for the $Q_{a}$ data series of ZS, LC, and FR in 1980, and that of in the cumulative $\mathrm{S}_{\mathrm{aZS}}-\mathrm{P}_{\mathrm{maZS}}$ and $\mathrm{S}_{\mathrm{aLC}}-\mathrm{P}_{\mathrm{maLC}}$ curves in 1959 due to construction of the reservoir. The former occurred later than the latter, which was mainly due to differential effects of the reservoir on the regulation of gradual flows and complete sediment deposition. The reservoir mainly supported farmland irrigation but has continually supplied water for industrial activities in Gujiao city within the ZS catchment and the Taiyuan city downstream of the LC station since the 1980s [47]. Five large underground coal mines and associated coal preparation plants were successively built in Gujiao city during period II. By the end of this period, the annual coal output reached 16.5 million tons and the total industrial output value of the city increased 36.3 times over that of 1978 when China's reform and opening-up policy was implemented [48]. Taiyuan city is an important industrial city in northern China and harbors industries with high water consumption (e.g., metallurgical, coal-fired, coking, and chemical industries) that accounted for $68.81 \%$ of the city's industrial output value in the early 1990s [49]. Dramatic decreases in $\mathrm{Q}_{\mathrm{aZS}}$ and $\mathrm{Q}_{\mathrm{aLC}}$ over period II were the result of industrial development in the two cities and the reservoir filling, which led to the increased water diversion from rivers, coupled with reduced rainfall, reduced incoming flows upstream, and the implementation of soil and water conservation measures. 
Moreover, extensive goafs from Gujiao coal mining activities could have intensified the infiltration of flows in leakage areas, thereby resulting in decreased runoff [50], as was observed by Cravotta et al. [51] in the upper Schuylkill River of Pennsylvania. These factors also contributed to decreased $S_{a z S}$ and $S_{a L C}$ values, as indicated by the second abrupt inflection of cumulative $S_{a z S}-P_{\text {maZs }}$ and $S_{a L C}-P_{\text {maLC }}$ curves in 1980 and the significant correlations in the $Q_{a}-S_{a}$ relationships for the two stations over this period $(p<0.05$ or $p<0.01)$.

The abrupt inflection points of cumulative $\mathrm{Q}_{\mathrm{a}}-\mathrm{P}_{\mathrm{ma}}$ curves for the SJY, ZS, and LC stations and those of the cumulative $S_{a}-P_{\text {ma }}$ curves for the four stations coincidently occurred in 1996. Previous hydrological records [52] indicated that catastrophic flood events occurred in the upper Fenhe River Basin in 1996 due to an extreme precipitation event when rainfall lasted for 34 hours and $314 \mathrm{~mm}$ of accumulated rainfall was measured at the rainfall center. A persistent five-year drought subsequently occurred during 1997-2001, with an average annual $P_{m a}$ value for the five years of $280 \mathrm{~mm}$, representing $78 \%$ of the average $\mathrm{P}_{\mathrm{ma}}$ for 1955-2015. These observations indicate that high magnitude flood events and climatic fluctuations are strongly coupled to fluxes in river discharge and sediment deposition [53]. However, significant correlations were not observed for the $Q_{a}-P_{m a}$ relationships for the three stations during this period, except for $Q_{a J L}-P_{\text {maJL }}$ of $J L$, nor for $S_{a}-P_{m a}$ at the four stations, or for $Q_{a L C}-T_{T Y}$ and $S_{\mathrm{aLC}}-\mathrm{T}_{\mathrm{TY}}$. These results could be primarily attributed to complex human activities that weaken the roles of climate change on the above values. As discussed earlier, 20 successive years of the "Soil and Water Conservation" program took place in the basin. By the end of 2007, 30341 $\mathrm{hm}^{2}$ of terraced fields, $131933 \mathrm{hm}^{2}$ of afforestation and grass, and 118 check dams had been developed in the upper reaches of the No. 1 Fenhe Reservoir [34]. These data provide some evidence for the effects of soil and water conservation measures on reduced $Q_{a}$ and $S_{a}$ values for JL and SJY during period III. Further evidence of this is given by the dramatic reduction in $\mathrm{D}_{\mathrm{aFR}}$ during this period (Figure 7a). The afforestation effects of the "Soil and Water Conservation," "Natural Forest Protection," and "Grain for Green" programs were confirmed by the significantly increased $\mathrm{NDVI}_{8 \mathrm{~km}}$ and $\mathrm{NDVI}_{250 \mathrm{~m}}$ values for the four catchments $(p<0.05$ or $p<0.01$ or $p<0.001)$. Moreover, the effects of sediment interception were represented by negative correlations for the $\mathrm{S}_{\mathrm{aJL}}-\mathrm{NDVI}_{8 \mathrm{kmJL}}, \mathrm{S}_{\mathrm{aZS}}-\mathrm{NDVI}_{8 \mathrm{kmZS}}$, and $\mathrm{S}_{\mathrm{aLC}}-\mathrm{NDVI}_{250 \mathrm{mLC}}$ relationships during this period $(p<0.05)$.

Booming industrial development and associated economies, along with urbanization, led to a continuous increase in water demand, thereby resulting in increased water diversion from rivers and dramatic decreases in runoff. The direct or indirect discharge of industrial wastewater and domestic sewage into rivers also led to the deterioration of water quality [47]. Consequently, severe water scarcity in industrial, agricultural, and domestic water occurred in Taiyuan city in the 1990s [54]. Concomitantly, over-exploitation of groundwater intensified, with the area of the deep groundwater depression cone near the lower reaches of LC station expanding by $44.8 \mathrm{~km}^{2}$ from 1990 to 2000 and central water levels dropping by $8.83 \mathrm{~m}$ [55]. As a result, the Yellow River Water Transfer Project was initiated in the basin, beginning in 2003, to primarily alleviate water scarcity in Taiyuan city. From 2003 to 2010, a total of 523 million $\mathrm{m}^{3}$ of Yellow River water had been supplied to Taiyuan city, and the annual water supply reached 320 million $\mathrm{m}^{3}$ by 2015 [56]. In addition, rapid urbanization development resulted in the development of a real estate industry. This was especially evident in the rapid development after 1998 upon implementation of China's urban housing system reform, as indicated by the increased FSBC $_{\text {TY }}$ during 1996-2015 (Figure 8). The result caused an increased demand for river sand, thereby contributing to increased sand excavation along the river due to the lack of any policy forbidding sand excavation during that time, and decreased $S_{a}$ values at the four stations. The above-mentioned factors profoundly influenced the spatiotemporal dynamics of rainfall-driven runoff generation and sediment delivery in the upper Fenhe River Basin, resulting in fundamentally changed $Q_{a}-S_{a}$ relationships at the four stations in period III (Figure 5). Similar results were reported by Xu [45] for the coarser sediment production area in the Middle Yellow River Basin. The comparably low reduction rate of $\mathrm{Q}_{\mathrm{aJL}}$ in period III compared with that in period I (when compared to the other three stations) was due to the transferred Yellow River water that largely supplemented $\mathrm{Q}_{\mathrm{aJL}}$ when passing through the river 
course upstream of the JL station. Conversely, the comparatively higher reduction of $\mathrm{S}_{\mathrm{aLC}}$ in period III than $S_{a Z s}$, when compared with values for period I, was caused by the construction of the No. 2 Fenhe Reservoir, which retained most of the sediments downstream of ZS after its commission in 2000.

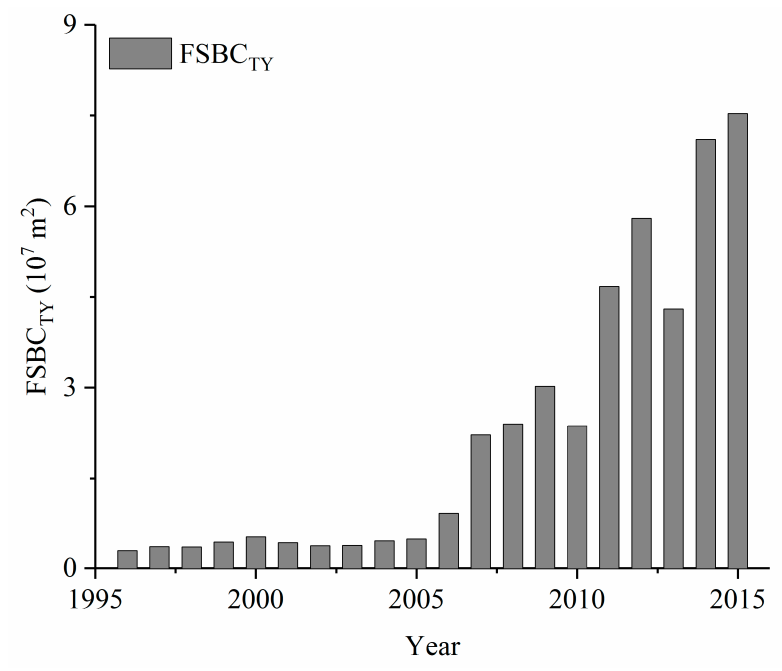

Figure 8. Temporal variation in the annual floor space data for buildings under construction in Taiyuan city $\left(\mathrm{FSBC}_{\mathrm{TY}}\right)$ values from 1996 to 2015.

\section{Summary and Conclusions}

In this study, temporal variation in $Q_{a}$ and $S_{a}$ values, as well as the $Q_{a}-S_{a}$ relationships, were investigated for four stations (JL, SJY, ZS, and LC) in the upper Fenhe River Basin during the period encompassing 1955-2015. The primary results showed that:

(1) $\mathrm{Q}_{\mathrm{a}}$ values for SJY, ZS, and LC dramatically decreased with average reduction rates of 0.68-1.07 $\mathrm{mm} \cdot \mathrm{km}^{-2} \cdot \mathrm{a}^{-1}$, and inflection points occurring around 1980, as shown using Mann-Kendall tests. The $S_{a}$ values at the four stations also significantly decreased, with average reduction rates of $9.24-54.39 \mathrm{t} \cdot \mathrm{km}^{-2} \cdot \mathrm{a}^{-1}$. The inflection points of $\mathrm{S}_{\mathrm{a}}$ occurred in 2004 for JL, 1997 for SJY, 1991 for ZS, and 1994 for LC.

(2) Decreased rainfall, soil and water conservation measures, and the construction of reservoirs were the primary factors underlying the decreased $Q_{a}$ and $S_{a}$ values for SJY, ZS, and LC during period II. The first two processes were responsible for the variation in $\mathrm{Q}_{\mathrm{aJL}}$ and $\mathrm{S}_{\mathrm{aJL}}$ during period II. Following 1997, dramatically decreased $Q_{a}$ and $S_{a}$ values, in addition to fundamental changes in the $Q_{a}-S_{a}$ relationships for the four stations, were primarily caused by increased anthropogenic activities, including water diversion, a cross-basin water transfer project, soil and water conservation measures, revegetation efforts, and sand excavation. In addition, construction of the No. 2 Fenhe Reservoir was also responsible for variation in $\mathrm{Q}_{\mathrm{aLC}}, \mathrm{S}_{\mathrm{aLC}}$, and the $\mathrm{Q}_{\mathrm{aLC}}-\mathrm{S}_{\mathrm{aLC}}$ relationship. In total, the influence of anthropogenic activities on $Q$ and $S$ was greater than that of climate change over the last 60 years in the upper Fenhe River Basin.

(3) The above results suggest that effective strategies should be stressed, including promoting the efficiency of water use, strengthening water resource management, etc., in order to adjust increasingly severe differences in water supplies and demands, as well as changed flow-sediment relationship in the upper Fenhe River Basin. In addition, the long-term impact of underground coal mining and a large-scale, cross-basin water transfer project on the environments of the upper Fenhe River should be an area of further concern and investigation.

Author Contributions: Conceptualization, L.Z. and S.L.; methodology, L.Z., Z.W., X.F., H.L., Q.M., and J.W.; writing and editing, L.Z. and S.L.; funding acquisition, L.Z. All authors have read and agreed to the published version of the manuscript. 
Funding: This research was funded by the Foundation for Young Scientists of Shanxi Province (grant number 2013021031-3), the National Natural Science Foundation of China (grant numbers 41301609 and U1810101), and the Applied Basic Research of Shanxi Province (grant number 201901D111040).

Acknowledgments: We thank anonymous editors from Letpub for the English language editing. We thank the editors and anonymous reviewers for their professional comments, which have helped us greatly improve the manuscript.

Conflicts of Interest: The authors declare no conflict of interest. The funders had no role in the design of the study; in the collection, analyses, or interpretation of data; in the writing of the manuscript, or in the decision to publish the results.

\section{References}

1. Tang, Y.; Tang, Q.; Tian, F.; Zhang, Z.; Liu, G. Responses of natural runoff to recent climatic variations in the Yellow River basin, China. Hydrol. Earth Syst. Sci. 2013, 17, 4471-4480. [CrossRef]

2. Hestir, E.L.; Schoellhamer, D.H.; Morgan-King, T.; Ustin, S.L. A step decrease in sediment concentration in a highly modified tidal river delta following the 1983 El Nino floods. Mar. Geol. 2013, 345, 304-313. [CrossRef]

3. Diffenbaugh, N.S.; Swain, D.L.; Touma, D. Anthropogenic warming has increased drought risk in California. Proc. Natl. Acad. Sci. USA 2015, 112, 3931-3936. [CrossRef] [PubMed]

4. Datsch Silveira, M.A.; Ribeiro, D.L.; Vieira, G.M.; Demarco, N.R.; Gregio d'Arce, L.P. Direct and Indirect Anthropogenic Contamination in Water Sources: Evaluation of Chromosomal Stability and Cytotoxicity Using the Allium cepa Test. Bull. Environ. Contam. Tox. 2018, 100, 216-220. [CrossRef] [PubMed]

5. Ouyang, Y.; Leininger, T.D.; Moran, M. Impacts of reforestation upon sediment load and water outflow in the Lower Yazoo River Watershed, Mississippi. Ecol. Eng. 2013, 61, 394-406. [CrossRef]

6. Gebremicael, T.G.; Mohamed, Y.A.; Betrie, G.D.; van der Zaag, P.; Teferi, E. Trend analysis of runoff and sediment fluxes in the Upper Blue Nile basin: A combined analysis of statistical tests, physically-based models and landuse maps. J. Hydrol. 2013, 482, 57-68. [CrossRef]

7. Syvitski, J.P.M.; Cohen, S.; Kettner, A.J.; Brakenridge, G.R. How important and different are tropical rivers?-An overview. Geomorphology 2014, 227, 5-17. [CrossRef]

8. Brusca, R.C.; Álvarez-Borrego, S.; Hastings, P.A.; Findley, L.T. Colorado River flow and biological productivity in the Northern Gulf of California, Mexico. Earth Sci. Rev. 2017, 164, 1-30. [CrossRef]

9. Dai, Z.J.; Fagherazzi, S.; Mei, X.F.; Gao, J.J. Decline in suspended sediment concentration delivered by the Changjiang (Yangtze) River into the East China Sea between 1956 and 2013. Geomorphology 2016, 268, 123-132. [CrossRef]

10. Gu, C.J.; Mu, X.M.; Gao, P.; Zhao, G.J.; Sun, W.Y. Changes in run-off and sediment load in the three parts of the Yellow River basin, in response to climate change and human activities. Hydrol. Process. 2019, 33, 585-601. [CrossRef]

11. Burn, D.H.; Elnur, M.A.H. Detection of hydrologic trends and variability. J. Hydrol. 2002, 255, 107-122. [CrossRef]

12. Walling, D.E.; Fang, D. Recent trends in the suspended sediment loads of the world's rivers. Glob. Planet Chang. 2003, 39, 111-126. [CrossRef]

13. Restrepo Juan, D.; Escobar Heber, A. Sediment load trends in the Magdalena River basin (1980-2010): Anthropogenic and climate-induced causes. Geomorphology 2018, 302, 76-91. [CrossRef]

14. Peng, J.; Chen, S.L.; Ping, D. Temporal variation of sediment load in the Yellow River basin, China, and its impacts on the lower reaches and the river delta. Catena 2010, 83, 135-147. [CrossRef]

15. Wei, Y.H.; Jiao, J.Y.; Zhao, G.J.; Zhao, H.K.; He, Z.; Mu, X.M. Spatial-temporal variation and periodic change in streamflow and suspended sediment discharge along the mainstream of the Yellow River during 1950-2013. Catena 2016, 140, 105-115. [CrossRef]

16. Zhang, J.J.; Zhang, X.P.; Rui, L.; Chen, L.L.; Lin, P.F. Did streamflow or suspended sediment concentration changes reduce sediment load in the middle reaches of the Yellow River? J. Hydrol. 2017, 546, 357-369. [CrossRef]

17. Xu, J.X.; Li, F.X. Response of lower Yellow River bank breachings to La Niña events since 924 CE. Catena 2019, 176, 159-169. [CrossRef]

18. Xu, J.X. Response of land accretion of the Yellow River delta to global climate change and human activity. Quatern. Int. 2008, 186, 0-11. [CrossRef] 
19. Li, B.Q.; Liang, Z.M.; Bao, Z.X.; Wang, J.; Hu, Y.M. Changes in streamflow and sediment for a planned large reservoir in the middle Yellow River. Land Degrad. Dev. 2019, 30, 878-893. [CrossRef]

20. Chen, K.; Su, J.L.; Wang, Y.G.; Chen, Y. Study on water-sediment relationship in the Yellow River. J. Sediment. Res. 2019, 44, 19-26.

21. Gao, G.Y.; Fu, B.J.; Zhang, J.J.; Ma, Y.; Sivapalan, M. Multiscale temporal variability of flow-sediment relationships during the 1950s-2014 in the Loess Plateau, China. J. Hydrol. 2018, 563, 609-619. [CrossRef]

22. Wang, S.; Fu, B.J.; Liang, W.; Liu, Y.; Wang, Y.F. Driving forces of changes in the water and sediment relationship in the Yellow River. Sci. Total. Environ. 2017, 576, 453-461. [CrossRef] [PubMed]

23. Han, J.Q.; Gao, J.N.; Han, L. Changes and implications of the relationship between rainfall, runoff and sediment load in the Wuding River basin on the Chinese Loess Plateau. Catena 2019, 175, 228-235. [CrossRef]

24. Walling, D.E. The sediment delivery problem. J. Hydrol. 1983, 65, 209-237. [CrossRef]

25. Yan, Y.X.; Xu, J.X. A study of scale effect on specific sediment yield in the Loess Plateau, China. Sci. China 2007, 50, 102-112. [CrossRef]

26. Zhao, G.J.; Mu, X.M.; Strehmel, A.; Tian, P. Temporal variation of streamflow, sediment load and their relationship in the Yellow River basin, China. PLoS ONE 2014, 9, e91048. [CrossRef] [PubMed]

27. Yang, J.S.; Liang, S.J.; Wang, J. Analysis of discontinuous flow of the Fenhe River. Yellow River 1998, 20, 3-6.

28. Zuo, H.F. Response of runoff in mid and upper reaches of Fenhe River to climate changes during the last 50 years. J. China Hydrol. 2006, 26, 72-75.

29. Department of Water Resources of Shanxi Province. Fenhe River Records; Shanxi People's Publishing House: Taiyuan, China, 2006.

30. Yao, W.X. Analysis on the sand production in the upstream basin of Fenhe reservoir. Shanxi Archit. 2007, 32, 361-362.

31. Ma, Z.Q. Vegetation in Shanxi Province; Science and Technology Press: Beijing, China, 2001.

32. Cui, W.; Wang, S.Y.; Zhang, H.; Ma, Y.J. Analysis on land-used cover change in the upper reaches of Fenhe River, China during 1976-1990. J. Shanxi Univer. Natur. Sci. Edit. 2008, 31, 141-146.

33. Ma, Y.J.; Hou, Z.H.; Xu, X.L. The impact of land use change on ecology-economy harmony degree in the upper reaches of Fenhe River watershed. J. Desert Res. 2012, 32, 1803-1808.

34. Qin, J.P. Effect of Soil and Water Conservation on Siltation in Upper Fenhe Reservoir Reaches. Soil Water Conserv. Sci. Tec. Shanxi 2016, 34-36.

35. Li, Z.; Liu, Y.Z.; Yan, X.; Ren, G.P.; Wang, Y.Q. Summarization and application of high-tech in to Wanjiazhai Projects. Eng. Mech. 2007, 24 (Suppl. II), 21-32.

36. NASA Modis Moderate Resolution Imaging Spectroradiometer. Available online: https://modis.gsfc.nasa. gov/data/dataprod/mod13.php (accessed on 20 June 2020).

37. Holben, B. Characteristics of maximum-value composite images from temporal AVHRR data. Int. J. Remote Sens. 1986, 7, 1417-1434. [CrossRef]

38. Bureau of Statistics in Shanxi Province. Shanxi Province Statistical Yearbook; China Statistics Press: Beijing, China, 1996-2015.

39. Fan, X.H.; Wang, Q.X.; Wang, M.B. Changes in temperature and precipitation extremes during 1959-2008 in Shanxi, China. Appl. Clim. 2012, 109, 283-303. [CrossRef]

40. Kendall, M.G. Rank Correlation Measures; Charles Griffin: London, UK, 1975.

41. Mann, H.B. Nonparametric test against trend. Econometrica 1945, 13, 245-259. [CrossRef]

42. Sen, P.K. Estimates of the Regression Coefficient Based on Kendall's Tau. Public Am. Stat. Assoc. 1968, 63, 1379-1389. [CrossRef]

43. Moraes, J.M.; Pellegrino, G.Q.; Bsllrdyrt, M.V.; Martinelli, L.A.; Victoria, R.L.; Krusche, A.V. Trends in Hydrological Parameters of a Southern Brazilian Watershed and its Relation to Human Induced Changes. Water Resour. Manag. 1998, 12, 295-311. [CrossRef]

44. Zhang, D.; Liu, X.M.; Liu, C.M.; Peng, B. Responses of runoff to climatic variation and human activities in the Fenhe River, China. Stoch. Environ. Res. Risk Assess. 2013, 27, 1293-1301. [CrossRef]

45. $\mathrm{Xu}, \mathrm{J} . \mathrm{X}$. Trend of sediment yield in the coarser sediment producing area in the middle Yellow River basin in the period 1997-2007 and the formative cause. J. Soil Water Conserv. 2010, 24, 1-7.

46. Niu, Q.S.; Niu, Y.J. Effect of construction of check dams and reservoirs in Lanhe River Basin, Lanxian County. Sci. Tec. Soil Water Conserv. Shanxi Pro. 1995, 1, 19-22.

47. Li, J. Analysis on the Inflow and Outflow of Fenhe reservoir. Sci. Tech. Inf. Dev. Econ. 2010, 20, $165-167$. 
48. History of Taiyuan. Available online: http://www.taiyuan.gov.cn/doc/2017/02/15/691195.shtml (accessed on 20 June 2020).

49. Rong, L.; Li, S.R. Thinking about solving the shortage of water resources in Taiyuan. Mod. Urban Res. 1995, 2, 38-42.

50. Ping, J.H.; Yan, S.Y.; Gu, P.; Wu, Z.N.; Hu, C.H. Application of MIKE SHE to study the impact of coal mining on river runoff in Gujiao mining area, Shanxi, China. PLoS ONE 2017, 12, e0188949. [CrossRef]

51. Cravotta, C.A., III; Goode, D.J.; Bartles, M.D.; Risser, D.W.; Galeone, D.G. Surface water and groundwater interactions in an extensively mined watershed, upper Schuylkill River, Pennsylvania, USA. Hydrol. Process. 2014, 28, 3574-3601. [CrossRef]

52. Li, Y.M. A Brief Record of Water Consevancy Important Events in Shanxi Province (1949-2002); Shanxi Science and Technology Press: Taiyuan, China, 2005.

53. Syvitski, J.P.M.; Kettner, A. Sediment flux and the Anthropocene. Philos Trans. R. Soc. A 2011, 369, 957-975. [CrossRef]

54. Ren, J.M.; Liu, Y.C.; Liang, A.Z. Influence of water resources on urban development of Taiyuan city and Countermeasures. Prod. Res. 2004, 2, 119-121.

55. Wu, S.L. Analysis on the development of the depression cone of deep groundwater level in Taiyuan City in recent 25 years. Shanxi Hydrotech. 2018, 1, 68-70.

56. Yuan, R.Q.; Zhang, W.X.; Wang, P.; Wang, S.Q. Impacts of water transfer from the Yellow River on water environment in the receiving area of the Fenhe River. J. Nat. Resour. 2018, 33, 1416-1426.

(C) 2020 by the authors. Licensee MDPI, Basel, Switzerland. This article is an open access article distributed under the terms and conditions of the Creative Commons Attribution (CC BY) license (http://creativecommons.org/licenses/by/4.0/). 